Chem Commun (Camb). 2017 November 16; 53(92): 12398-12401. doi:10.1039/c7cc07023c.

\title{
Perdeuterated and ${ }^{13} \mathrm{C}$-enriched myo-inositol for DNP assisted monitoring of enzymatic phosphorylation by inositol-3-kinase
}

\author{
M. J. Moure ${ }^{a,+}$, Y. Zhuo ${ }^{a,+}$, G. J. Boons ${ }^{a,{ }^{*}}$, and J. H. Prestegard ${ }^{a,{ }^{*}}$ \\ aComplex Carbohydrate Research Center, University of Georgia, Athens GA 30602
}

\begin{abstract}
The synthesis of perdeuterated and ${ }^{13} \mathrm{C}$ enriched myo-inositol is presented. Myo-inositol and its derivatives are of interest as substrates for enzymes producing phosphorylated species with regulatory functions in many organisms. Its utility in monitoring real-time phosphorylation by myo-inositol-3-kinase is illustrated using dynamic nuclear polarization (DNP) to enhance NMR observation.
\end{abstract}

\section{Graphical abstract}

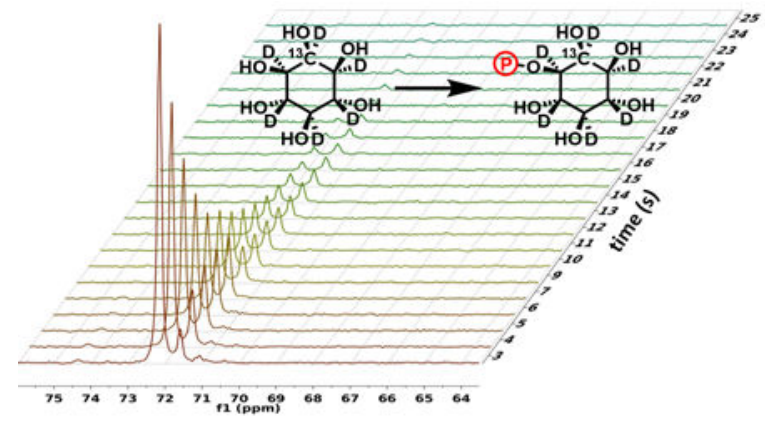

Inositols represent an important class of biologically active molecule. Of the nine possible stereoisomers, myo-inositol is generally the most abundant. ${ }^{1}$ It occurs in its free form in many tissues. It is, for example, especially rich in the brain and its distribution there can be used to monitor the health status of brain. ${ }^{2}$ It is also a constituent of the glycosylphosphatidylinositol (GPI) moieties that anchor many proteins to membrane surfaces, ${ }^{3}$ phosphorylated forms, inositol phosphates, are important intra-cellular signalling molecules ${ }^{4,5}$ and lipid derivatives, phosphatidylinositides, are important modulators of membrane function. ${ }^{6}$ Given their broad distribution and involvement in biological function, monitoring the levels of inositols and their conversion to metabolic products is of considerable interest. Characterization of metabolites extracted from cell and tissue samples by NMR or mass spectrometry is commonly applied as means of monitoring metabolite

\footnotetext{
"Corresponding authors, jpresteg@ccrc.uga.edu, gjboons@ccrc.uga.edu.

+These authors contributed equally to the work.

Electronic Supplementary Information (ESI) available: detailed methods of synthesis, protein expression, and data analysis. See DOI: 10.1039/x0xx00000x

Conflicts of interest: There are no conflicts to declare.
} 
levels. ${ }^{7,8}$ However, recent advances in real time observation of metabolic conversion using dynamic nuclear polarization (DNP) to enhance NMR observation have made application of this technology particularly appealing. ${ }^{9-11}$ In these applications, isotopically labelled forms of a metabolic precursor are often required. ${ }^{12}$ Here we present methods to produce a perdeuterated form of ${ }^{13} \mathrm{C}$-C2-myo-inositol that is particularly useful in real-time monitoring of its metabolic conversions using DNP enhanced NMR, and we illustrate that utility by monitoring enzymatic conversion to inositol-3-phosphate by myo-inositol 3-kinase.

A number of different approaches to obtaining optically pure carbocyclic polyols have been developed in the past, ${ }^{13}$ and some of these are particularly appropriate for preparation of isotopically labelled inositols. ${ }^{1,}{ }^{14}$ In Scheme 1, we outline a highly stereo-selective route to the synthesis of perdeuterated and ${ }^{13} \mathrm{C}$ enriched myo-inositol beginning with $\mathrm{D}$ Glucose-1-13 $\mathrm{C}(2)$ that builds on this precedent. It begins with preparation of a suitably protected and stereo-chemically defined the sugar moiety for subsequent conversion to a carbocyclic polyol. Fischer glycosidation of D-Glucose-1-1 ${ }^{13} \mathrm{C} 2$ first yielded the corresponding methylglucopyranoside 3 . The O-6 hydroxyl group was then selective protected to afford sylilated $\mathbf{4}$ and then benzylated with benzyl bromide and sodium hydride to give 5. Interestingly, $79 \%$ of the mixture was retained as the a-anomer without silyl group migration as previously observed. ${ }^{15}$ This may stem from our use of a bulky tetrabutylammonium iodide adjuvant in this reaction. The mixture was separated by column chromatography to obtain the pure a-anomer (5).

Analysis of the 1H NMR spectrum of 5 showed that the ${ }^{13} \mathrm{C}$-coupled signals for the anomeric hydrogen $\mathrm{H}-1$ at $\delta 4.90$ and 4.35 ppm had coupling constants of ${ }^{1} \mathrm{~J}_{\mathrm{C} 1, \mathrm{H} 1}=177.5$ and ${ }^{1} \mathrm{~J}_{\mathrm{H} 1, \mathrm{H} 2}=3.5 \mathrm{~Hz}$, indicative of a a-linkage at the anomeric carbon.

Deprotection of the silyl protecting group using tetrabutylammonium fluoride delivered $\mathbf{6}$ in high yield. Oxidation of methyl 2,3,4-tri-O-benzylglycoside by the Dess-Martin oxidation procedure provided the corresponding unstable aldehyde $\mathbf{7}$, which was immediately treated with acetic anhydride in presence of appropriate base to afford the desired enol acetate $\mathbf{8}$ in $50 \%$ yield over two steps. The $\mathrm{Z}$-isomer was predominantly obtained, and could be isolated through column separation. Treatment of glucoside Z-isomer $\mathbf{8}$ with a stoichiometric amount of $\mathrm{Hg}$ (II) salt in aqueous acetone at room temperature for $8 \mathrm{~h}$ afforded the penta-oxygenated cyclohexanone in $32 \%$ yield as a 80:20 diastereoisomeric mixture $\mathbf{9}$. Mercury(II)-mediated rearrangement of a hex-5-enopyranoside derivative is generally termed the Ferrier (II) reaction. ${ }^{16,17}$ In this cyclization, the carbanionic center (C6) attacks the electrophilic carbonyl center $(\mathrm{C} 1)$. The stereochemistry of the newly formed asymmetric center is influenced by the conformation bias of the molecule, the chemical nature of the functionalities present, and the reaction conditions. Literature indicates that employing $\mathrm{PdCl}_{2}$ in this step is of higher efficacy compared with $\mathrm{Hg}\left(\mathrm{OCOCF}_{3}\right)_{2}$, but the coordination effect of the palladium salt to a $\mathrm{C}-\mathrm{C}$ double bond also provides more than two diastereoisomers. ${ }^{18}$ With the pure hex-5-enopyranoside 9 in hand, stereoselective reduction of the carbonyl group is crucial in obtaining the benzylated myo-inositol 11 with a minimum of unnatural diastereoisomers. The employment of $\mathrm{Me}_{4} \mathrm{NBH}(\mathrm{OAc})_{3}$ provided anti diols in good yield with excellent diastereoselectivity at 10 (99:1). Deprotection by the acetyl group at C-1 was carried out under mild conditions with guanidinium chloride / sodium ethoxide, ${ }^{19}$ 
and the catalytic debenzylation of the pure structure 11 with $20 \% \mathrm{Pd} / \mathrm{C}$ and hydrogen at atmospheric pressure afforded compound $\mathbf{1 2}$. The stereochemistry and the preferred conformer of the synthesized product is easily confirmed by inspection of the 2D COSY spectrum in Figure 1. In particular, inositol 1 having a symmetry plane through C-1 and C-4, shows a connection of the ${ }^{13} \mathrm{C}$-coupled $\mathrm{H} 2$ resonance at 4.17 and $3.66 \mathrm{ppm}\left({ }^{1} \mathrm{~J}_{\mathrm{C}-2, \mathrm{H}-2}=\right.$ $148.7 \mathrm{~Hz})$ to degenerate $\mathrm{H} 1$ and $\mathrm{H} 3$ resonances with a small ${ }^{1} \mathrm{H}-{ }^{1} \mathrm{H}$ coupling $\left({ }^{1} \mathrm{~J}_{\mathrm{H}-1, \mathrm{H}-2}=2.7\right.$ $\mathrm{Hz}$ ) and moderate two-bond ${ }^{1} \mathrm{H}_{-}{ }^{13} \mathrm{C}$ coupling, indicating an axial hydroxyl group at $\mathrm{C} 2$. Other ${ }^{1} \mathrm{H}-{ }^{1} \mathrm{H}$ couplings are large indicating equatorial hydroxyl groups at the other carbons.

Hydrogen atoms of many carbohydrates which are bonded to carbon atoms having a free hydroxyl group readily undergo ${ }^{1} \mathrm{H}-{ }^{2} \mathrm{H}$ exchange in deuterium oxide in the presence of Raney nickel catalyst. ${ }^{20,21}$ Although the replacement of ${ }^{1} \mathrm{H}$ by ${ }^{2} \mathrm{H}$ takes place primarily with retention of configuration, inversion is also frequently observed. ${ }^{22}$ In 2010, Fujiwara and collaborators found that ruthenium on carbon efficiently catalyzed the chemoselective H-D exchange reaction on the carbons adjacent to the hydroxyl groups of primary and secondary aliphatic alcohols in neutral $\mathrm{D}_{2} \mathrm{O}$ under atmospheric $\mathrm{H}_{2} \cdot{ }^{23}$ Employing their conditions we have achieved the regioselective $\mathrm{H}-\mathrm{D}$ exchange reaction of myo-inositol using the $\mathrm{Ru} / \mathrm{C}-\mathrm{H}_{2}-$ $\mathrm{D}_{2} \mathrm{O}$ combination. While equatorial hydrogen atoms $(\mathrm{H}-2)$ exchange more rapidly than do axial ones, ${ }^{24}$ deuteration proceeded with high efficiency and regioselectivity under mild reaction conditions without any structural changes (see Supplementary Information). An explanation of the retention of configuration is that the molecule is adsorbed so strongly to the catalytic surface that is does not alter its position relative to the surface during the hydrogen-deuterium exchange reaction.

To illustrate the utility of the ${ }^{13} \mathrm{C}$-labeled, perdeuterated, product we describe its use in monitoring conversion to myo-inositol-3-phosphate by the action of myo-inositol-3-kinase using DNP-enhanced NMR. NMR observation of metabolic products is primarily limited by NMR's relatively low sensitivity. DNP offers a solution by exposing precursors to low temperature $(\sim 1.5 \mathrm{~K})$ in the presence of a more polarizable entity (a free radical species) and transferring the resulting Boltzmann enhanced magnetic polarization to nuclear spins for observation. ${ }^{11}$ In dissolution DNP the polarized sample is quickly dissolved in warm buffer and transferred to a sample awaiting observation in a nearby spectrometer. Using this methodology enhancements in ${ }^{13} \mathrm{C}$ sensitivity by as much as four orders of magnitude have been observed. ${ }^{10}$ When real-time monitoring of conversion is desired, this enhanced sensitivity is parsed out over time using a series of small radio frequency (rf) pulse angles rather than the commonly used $90^{\circ}$ pulse angle. However, the time frame for observation is short due to spin relaxation coming from protons directly attached to, or very near, ${ }^{13} \mathrm{C}$ enriched sites. Most observations are, therefore, made with ${ }^{13} \mathrm{C}$ in non-protonated sites (carbonyl carbons). When non-protonated sites are absent, as in myo-inositol, the replacement of protons with deuteriums provides an alternative approach that decreases relaxation rates by as much as a factor of $15.9 .^{25}$ Hence, the need for a perdeuterated form of myo-inositol.

Phosphorylation at the 3 position of inositol is an important step in the synthesis of several membrane anchored regulatory molecules including phosphatidylinositol 3-phosphate (PI(3)P), phosphatidylinositol $(3,4)$-bisphosphate $(\mathrm{PI}(3,4) \mathrm{P} 2)$, and phosphatidylinositol 
$(3,4,5)$-trisphosphate $(\mathrm{PI}(3,4,5) \mathrm{P} 3)$. Synthesis in these cases is accomplished by action of phospatidylinositol-3-kinases acting on membrane anchored precursors. These proteins have been targeted in the development of drugs for the treatment of cancer, neurological disease and immunological disorders. ${ }^{26,}{ }^{27}$ In some archaea and plants enzymatic phosphorylation at the 3 position of soluble myo-inositol also occurs. ${ }^{28,}{ }^{29}$ Interestingly, small peptides have been found to catalyse similar stereo-specific phosphorylation. ${ }^{30}$ Here, we use the TK2285 gene product from Thermococcus kodakarensis (myo-inositol- 3-kinase, EC 2.7.1.64) as an easily accessible system to illustrate the spectral changes that occur on phosphorylation of inositol containing substrates, and the advantages of DNP-enhanced NMR.

The stacked plot in Figure 2 shows $1 \mathrm{D}{ }^{13} \mathrm{C}$ spectra of the hyper-polarized $\left[{ }^{13} \mathrm{C} 2\right.$, u-D $]$-myoinositol and its phosphorylated product collected at $1.5 \mathrm{sec}$ intervals after mixing with myoinositol-3-kinase. The peaks at $72.3 \mathrm{ppm}$ and $71.8 \mathrm{ppm}$ were assigned to the $\mathrm{C} 2$ of myoinositol and myo-inositol-3-phosphate (MI3P), respectively. The first two scans are blank due to the delay in transfer of polarized substrate to the magnet after dissolution. The injection of substrate was completed in $1.5 \mathrm{sec}$, resulting in the near instantaneous appearance of a signal for myo-inositol that then decays exponentially with time over the next 10 to 20s. In contrast, a slow build-up of concentration is observed for the product (MI3P). The signal then decays, but signal is observable out to approximately $30 \mathrm{~s}$.

The time courses for both substrate (myo-inositol) and product (MI3P) can be fit to a model that is composed of two parts, a part that relates directly to time dependent signals from metabolites due to chemical conversion and spin relaxation, and a part that converts concentrations to NMR signals, correcting for repetitive effects of rf pulses. ${ }^{31}$ Treating these parts separately is advantageous since the first is described by continuous functions and the second by discrete sets of observation points (described in Supplementary Information). The extracted peak intensities and best-fit curves for data from duplicate runs are shown in Figure 3 . The primary parameters in the fitting equations are $T_{1}$ relaxation times for the substrate and product, the rf pulse angles and the rate constant for enzymatic conversion. The $T_{1} \mathrm{~s}$ are not well determined because attenuation of signal is primarily due to repetitive pulsing with rf pulses at the best fit angle. Of more interest is the pseudo first-order rate constant $\left(\mathrm{k}_{\mathrm{enz}}\right)$ for conversion of product to substrate, $0.07+/-0.02 \mathrm{~s}^{-1}$. Assuming saturation kinetics and taking into account the amount of enzyme $(2.6 \mathrm{mg})$ and amount of substrate in the NMR tube (18.0 $\mu \mathrm{mol})$ this can be converted to an enzyme activity of $30 \mu \mathrm{mol} \mathrm{min}{ }^{-1}$ $\mathrm{mg}^{-1}$. This can be compared to values in the literature of $44 \mu \mathrm{mol} \mathrm{min}{ }^{-1} \mathrm{mg}^{-1}{ }^{29}$ This is reasonable agreement considering that our measurements are at approximately $30^{\circ} \mathrm{C}$ as compare to $85^{\circ} \mathrm{C}$ for literature data; Thermococcus kodakarensis is a hyperthermophile and may have enhanced activity at higher temperatures.

In summary, we have reported an effective synthesis of ${ }^{13} \mathrm{C}$ enriched and perdeuterated myoinositol. Isotopically labelled versions of this molecule are potentially useful in a variety of metabolic studies, whether based on NMR or MS observation. The general methodology for preparation may also be extendable to preparation of phosphatidylinositide substrates. Our illustration of enzyme catalyzed conversion of a substrate hyperpolarized using DNP also points the way to real-time monitoring by NMR in cellular systems that may use myoinositol as a substrate, as well as other in vivo systems where inositides may be of interest. 


\section{Supplementary Material}

Refer to Web version on PubMed Central for supplementary material.

\section{Acknowledgments}

This work was supported by grants from the National Institutes of Health (US), R21-EB017862 and P01GM107012. Manuscript content is solely the responsibility of the authors and does not necessarily represent the official views of the National Institutes of Health.

\section{Notes and references}

1. Thomas MP, Mills SJ, Potter BV. Angew Chem Int Ed Engl. 2016; 55:1614-1650. [PubMed: 26694856]

2. Haris M, Cai K, Singh A, Hariharan H, Reddy R. Neuroimage. 2011; 54:2079-2085. [PubMed: 20951217]

3. Yu SC, Guo ZW, Johnson C, Gu GF, Wu QY. Current Opinion in Chemical Biology. 2013; 17:10061013. [PubMed: 24128440]

4. Berridge MJ, Irvine RF. Nature. 1989; 341:197-205. [PubMed: 2550825]

5. Garcia CRS, Alves E, Pereira PHS, Bartlett PJ, Thomas AP, Mikoshiba K, Plattner H, Sibley LD. Current Topics in Medicinal Chemistry. 2017; 17:2158-2165. [PubMed: 28137231]

6. Bridges D, Saltiel AR. Biochimica Et Biophysica Acta-Molecular and Cell Biology of Lipids. 2015; 1851:857-866.

7. Bingol K, Bruschweiler R. Current Opinion in Biotechnology. 2017; 43:17-24. [PubMed: 27552705]

8. Markley JL, Bruschweiler R, Edison AS, Eghbalnia HR, Powers R, Raftery D, Wishart DS. Current Opinion in Biotechnology. 2017; 43:34-40. [PubMed: 27580257]

9. Ardenkjaer-Larsen JH. Journal of Magnetic Resonance. 2016; 264:3-12. [PubMed: 26920825]

10. Ardenkjaer-Larsen JH, Fridlund B, Gram A, Hansson G, Hansson L, Lerche MH, Servin R, Thaning M, Golman K. Proceedings of the National Academy of Sciences of the United States of America. 2003; 100:10158-10163. [PubMed: 12930897]

11. Lumata, L., Yang, CD., Ragavan, M., Carpenter, N., DeBerardinis, RJ., Merritt, ME. Metabolic Analysis Using Stable Isotopes. Metallo, CM., editor. Vol. 561. 2015. p. 73-106.

12. Keshari KR, Wilson DM. Chemical Society Reviews. 2014; 43:1627-1659. [PubMed: 24363044]

13. Ferrier RJ, Middleton S. Chem Rev. 1993; 93:2779-2831.

14. Sasaki K, Taylor IE. Plant Physiol. 1986; 81:493-496. [PubMed: 16664844]

15. Wang W, Li XL, Zhang PZ, Chen H. Chinese J Chem. 2008; 26:208-212.

16. Dalko PI, Sinay P. Angew Chem Int Edit. 1999; 38:773-777.

17. Tian F, Migaud ME, Frost W. J Am Chem Soc. 1999; 121:5795-5796.

18. Takahashi H, Kittaka H, Ikegami S. J Org Chem. 2001; 66:2705-2716. [PubMed: 11304191]

19. Ellervik U, Magnusson G. Tetrahedron Letters. 1997; 38:1627-1628.

20. Cioffi EA, Prestegard JH. Tetrahedron Letters. 1986; 27:415-418.

21. Koch HJ, Stuart RS. Carbohydrate Research. 1977; 59:C1-C6.

22. Sasaki K, Balza F, Taylor IEP. Carbohydr Res. 1987; 166:171-180.

23. Fujiwara Y, Iwata H, Sawama Y, Monguchi Y, Sajiki H. Chem Commun (Camb). 2010; 46:49774979. [PubMed: 20544123]

24. Angyal SJ. Carbohydr Res. 1983; 123:13-22.

25. Allouche-Arnon H, Lerche MH, Karlsson M, Lenkinski RE, Katz-Brull R. Contrast Media \& Molecular Imaging. 2011; 6:499-506. [PubMed: 22144028]

26. Huynh A, Zhang R, Turka LA. Immunological Reviews. 2014; 258:117-131. [PubMed: 24517429]

27. Papadatos-Pastos D, Rabbie R, Ross P, Sarker D. Critical Reviews in Oncology Hematology. 2015; 94:18-30. 
28. Nagata R, Fujihashi M, Sato T, Atomi H, Miki K. Biochemistry. 2015; 54:3494-3503. [PubMed: 25972008]

29. Sato T, Fujihashi M, Miyamoto Y, Kuwata K, Kusaka E, Fujita H, Miki K, Atomi H. Journal of Biological Chemistry. 2013; 288:20856-20867. [PubMed: 23737529]

30. Sculimbrene BR, Morgan AJ, Miller SJ. Chem Commun. 2003; 15:1781-1785.

31. Zhuo Y, Cordeiro CD, Hekmatyar SK, Docampo R, Prestegard JH. Journal of Biological Chemistry. 2017; doi: 10.1074/jbc.M117.807495 


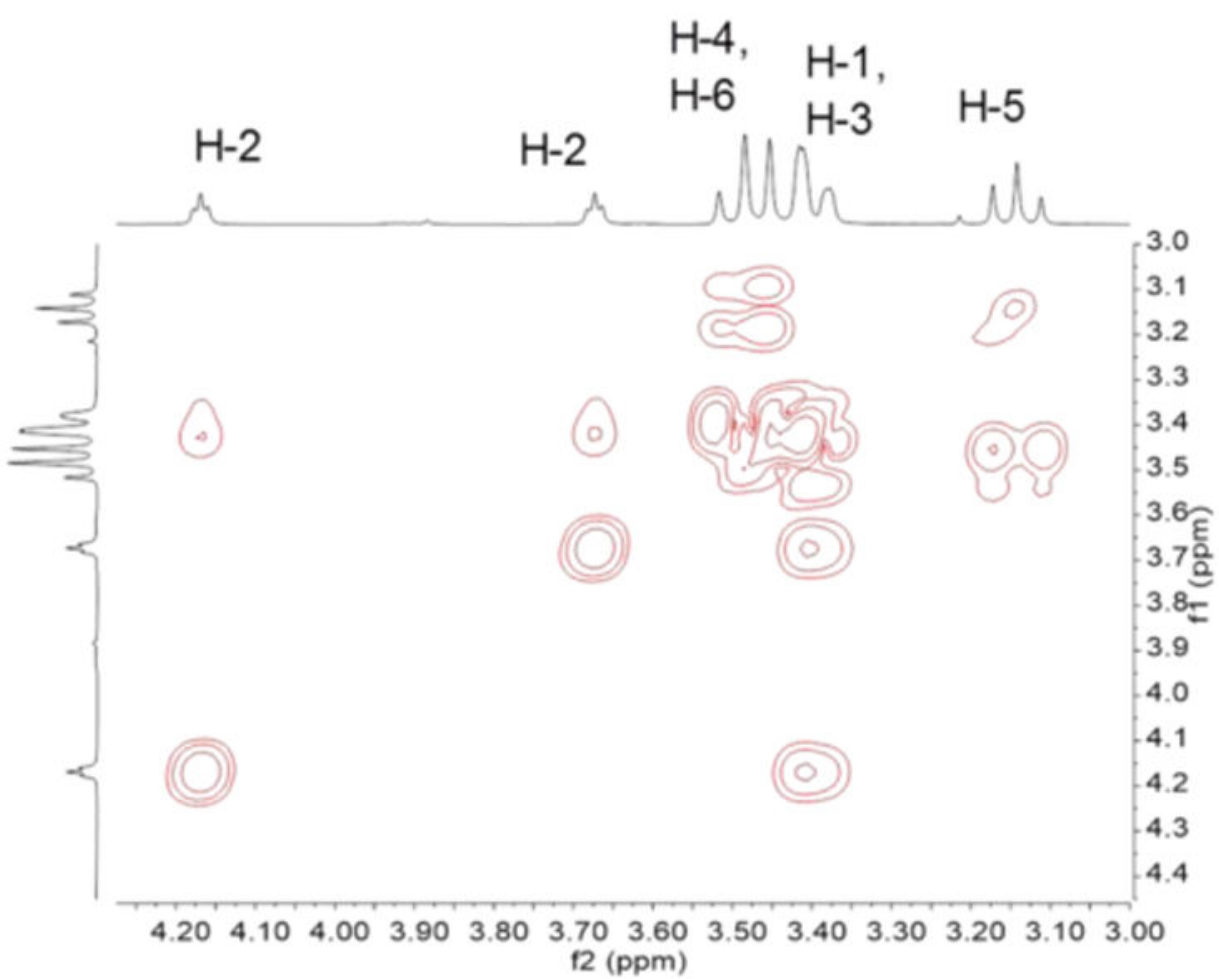

Fig. 1.

The $1 \mathrm{H}-1 \mathrm{H}$ COSY spectrum of myo-inositol (1) in $\mathrm{H}_{2} \mathrm{O}$ showing signal assignments. 


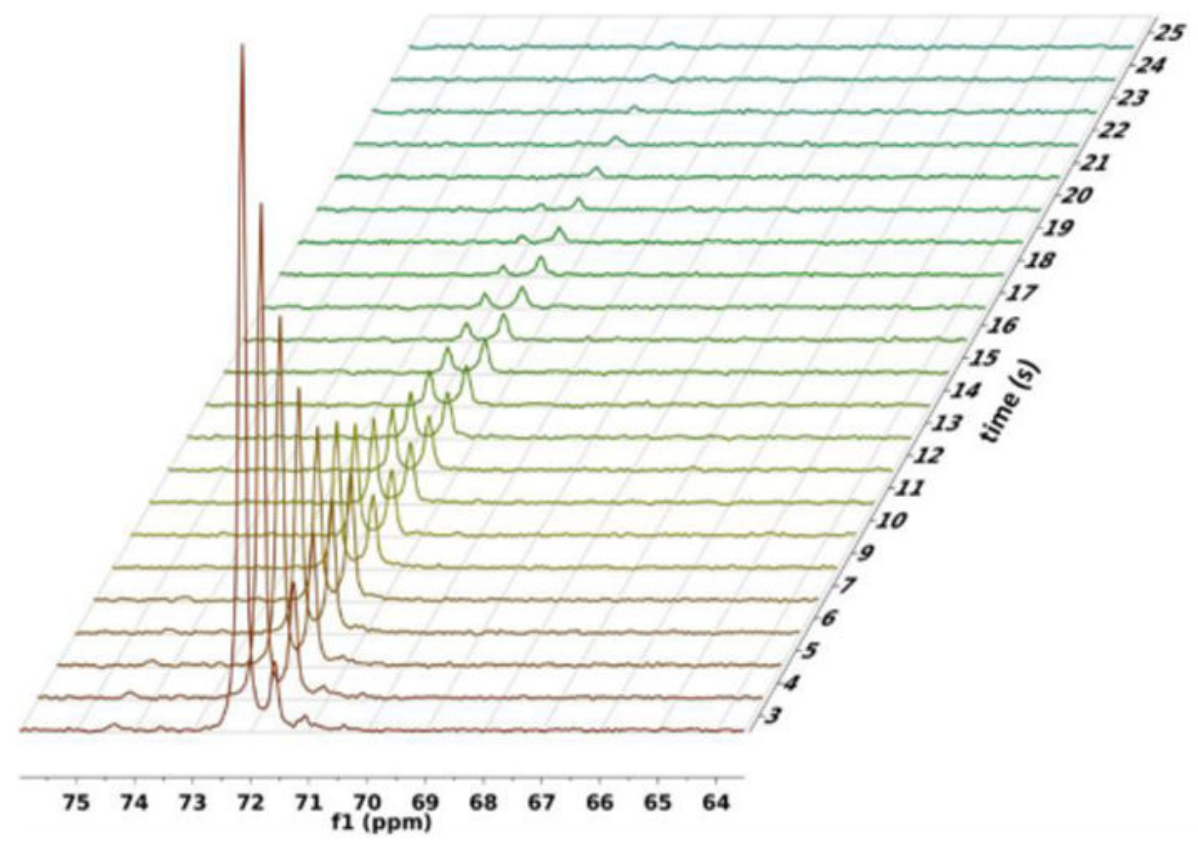

Fig. 2.

DNP time course of myo-inositol 3-kinase reaction. ${ }^{13} \mathrm{C}$ spectra are at $125 \mathrm{MHz} . \mathrm{C} 2$ resonances of myo-inositol and MI3P are at 73.2 and $71.8 \mathrm{ppm}$, respectively. 


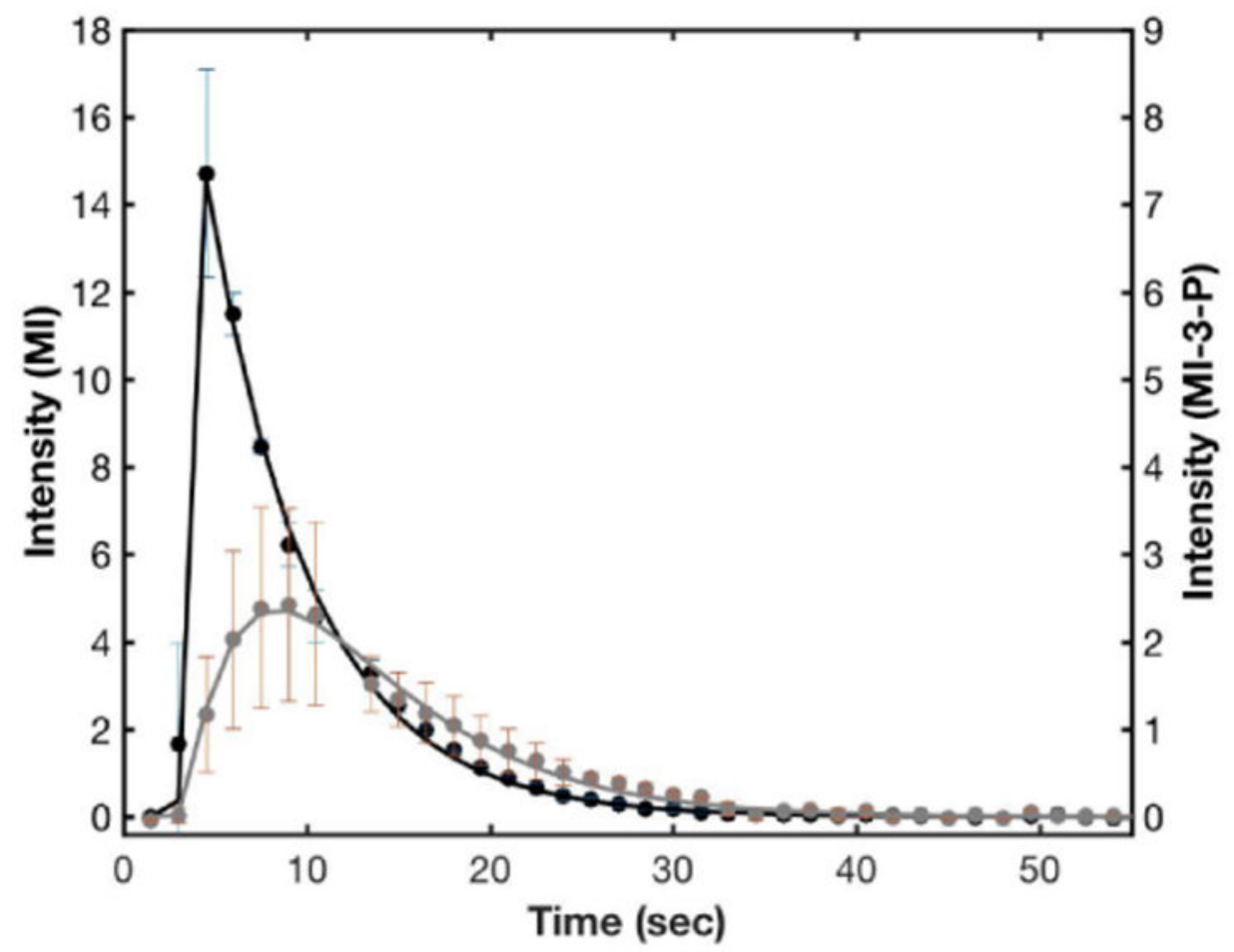

Fig. 3.

Simultaneous fitting of substrate and product using kinetic parameters as described in Supplementary Information. Black symbols are for myo-inositol; Gray symbols are for myoinositol-3-phosphate. Error bars are standard deviations from duplicate runs. 

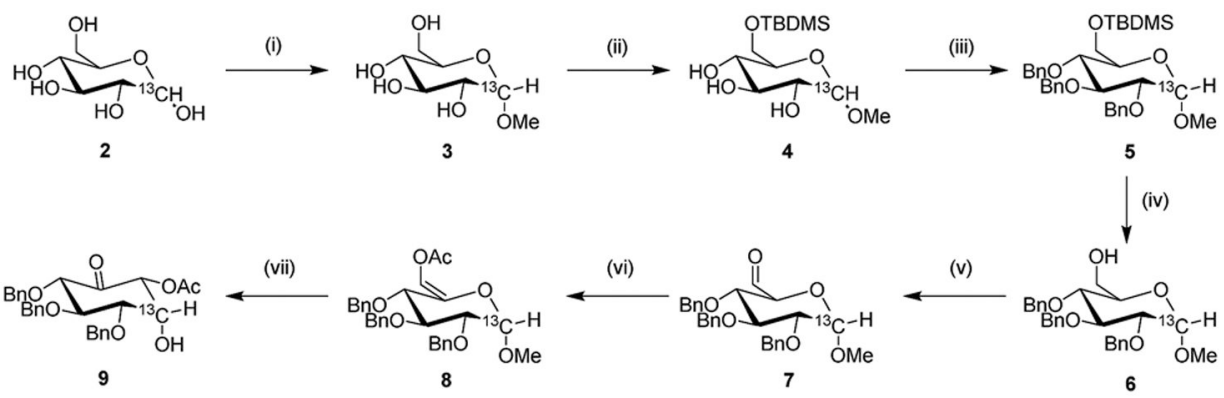

(viii)

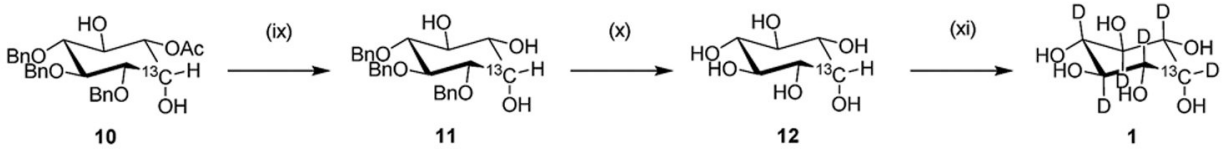

Scheme 1.

Synthesis of the perdeuterated myo-inositol-2- ${ }^{13} \mathrm{C} \mathbf{1}$.

Reagents and conditions: (i) $\mathrm{AcCl}, \mathrm{MeOH}$, r.t, quantitative; (ii) $\mathrm{TBDMSCl}_{2} \mathrm{Et}_{3} \mathrm{~N}$, DMAP, DMF, r.t., 4 (90\%); (iii) BnBr, NaH, TBAI, DMF, r.t., 5 (79\%); (iv) TBAF, THF, r.t., 6 (67\%); (v) Dess-Marting reagent, DCM, r.t.; (vi) $\mathrm{Ac}_{2} \mathrm{O}, \mathrm{Et}_{3} \mathrm{~N}$, DMAP, $45{ }^{\circ} \mathrm{C}, 8$ (50\% two steps); (vii) $\mathrm{Hg}\left(\mathrm{OCOCF}_{3}\right)_{2}$, acetone- $\mathrm{H}_{2} \mathrm{O}$, r.t., 9 (32\%); (viii) $\mathrm{Me}_{4} \mathrm{NBH}(\mathrm{OAc})_{3}, \mathrm{CH}_{3} \mathrm{CN}$ $\mathrm{AcOH}$, r.t., 10 (92\%); (ix) Guanidinium Cl/NaOEt, r.t., 11 (97\%); (x) $\mathrm{H}_{2}, \mathrm{Pd}(\mathrm{OH})_{2}$, $\mathrm{MeOH}$, r.t., 12 (99\%); (xi) $\mathrm{H}_{2}, \mathrm{Ru} / \mathrm{C}, \mathrm{D}_{2} \mathrm{O}, 80{ }^{\circ} \mathrm{C}, 1$ (84\%). 